\title{
Prevention of Liver Fibrosis and Cancer in Africa: The PROLIFICA project - a collaborative study of hepatitis B-related liver disease in West Africa
}

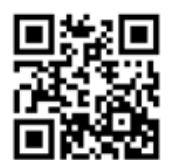

\author{
Hepatitis B and hepato- \\ cellular carcinoma in sub- \\ Saharan Africa (SSA)
}

Hepatitis B virus (HBV) infection causes a spectrum of acute and chronic liver disease ranging from inactive chronic carrier status to progressive chronic hepatitis, culminating in end-stage cirrhosis and liver cancer. ${ }^{[1]}$ In SSA, HBV infection is endemic and the HBV-related disease burden is high. The lifetime risk of HBV infection is over $60 \%$, and more than $8 \%$ of the population remain chronic HBV carriers who are at risk of progressive liver disease and HBV-related hepatocellular carcinoma (HCC). SSA has one of the highest HBV-related liver cancer rates in the world, ${ }^{[2]}$ and it is the most common cancer among males and third most common among females. ${ }^{[3,4]}$ Unfortunately, HCC is usually a highly aggressive tumour with limited treatment options, particularly in resource-poor settings such as SSA. ${ }^{[5]}$ Furthermore, HBV-related HCC affects patients in their working and reproductive years. ${ }^{[5]} \mathrm{HBV}$ therefore represents a threat to health on the African continent.

Early detection and treatment of HBV infection reduces HCC incidence and mortality (primary prevention). ${ }^{[6,7]}$ Furthermore, HCC survival is improved by early detection of potentially treatable HCC by screening of patients at risk. ${ }^{[8]}$ However, limited access to affordable medical care is a major limiting factor in hepatitis and liver cancer management in SSA. Routine HBV and HCC screening and surveillance programmes for the general population are virtually nonexistent, and there is a lack of infrastructure to support channelling of screened patients into long-term treatment programmes. ${ }^{[9]}$

Safe and effective treatments for HBV exist, but in SSA treatment access is severely limited. Despite highly effective nucleoside analogues such as tenofovir being available in most countries in SSA at a generic price for the treatment of HIV infection, very few African countries offer publicly funded HBV treatment. ${ }^{[9]}$

\section{Prevention of hepatitis B-related liver fibrosis and cancer in Africa: The PROLIFICA study}

Against this sombre backdrop of HBV-related liver disease in SSA, the Prevention of Liver Fibrosis and Cancer in Africa (PROLIFICA) project was established in 2011 to address some of the urgent HBV research needs in West Africa. This is an ongoing 5-year translational research project funded by the European Union Framework $7^{[10]}$ and represents a collaboration between Imperial College, London; the Medical Research Council (The Gambia Unit) in Fajara, The Gambia; the International Agency for Research on Cancer, Lyon, France; Le Dantec University Hospital, Dakar, and University of Thiès, Sénégal; and Jos University Teaching Hospital, Jos, Nigeria.

The overall aim of the project is to reduce the incidence of HBVrelated HCC in West Africa. The three specific aims of the project are demonstrating the feasibility of widespread screening for HBVrelated liver disease; establishing whether treatment of HBV with nucleoside analogues is a cost-effective method to reduce the burden of HBV-related liver disease and liver cancer in West Africa; and developing novel biomarkers to predict and diagnose HBV-related liver fibrosis and HCC.

\section{Achievements of the PROLIFICA project so far}

To date, the PROLIFICA study has provided important insights into HBV-related HCC in West Africa, including identification of novel metabonomic biomarkers that may prove useful for HCC diagnosis in resource-poor settings; ${ }^{[1,12]}$ identification of genomic determinants of HCC and epidemiological insights into risks for more severe HBVrelated liver disease; ${ }^{[13]}$ validation of point-of-care tests for HBV (manuscript in submission) and the optimal use of the Fibroscan to measure liver stiffness ${ }^{[14]}$ as a surrogate imaging marker for liver fibrosis; and the non-invasive aspartate aminotransferase-to-platelet ratio (APRI score) to determine the severity of liver cirrhosis from simple blood tests (manuscript in submission).

Importantly, the PROLIFICA platform has resulted in crucial capacity building in each of the three countries involved in the study. Local health infrastructure has benefited from new technologies, such as the Fibroscan to assess liver fibrosis using ultrasound-based transient elastography, a mass spectroscopy system in The Gambia for local biomarker research and the development of in-house laboratory assays, as well as skills transference to build capacity for improved liver cancer healthcare in West Africa.

Local nursing, medical and laboratory staff have benefited from training, education and employment opportunities. Procedures and training in effective and secure data management and ethical research practices have also been a central part of the PROLIFICA platform. Local researchers have availed themselves of specialised academic mentorship at each of the three sites involved in the study to obtain higher research degrees and produce highly regarded academic publications. Finally, community education on HBV infection, mode of transmission and prevention is likely to have had a positive impact on HBV awareness, both at the community and political level.

Above all, the PROLIFICA platform has facilitated the development of strong relationships for future research collaborations and a deeper understanding of the barriers to improved healthcare delivery in Africa. All centres have benefited equally from the experience and knowledge shared between the investigating teams. Arguably these are the greatest achievements of the project. International collaborative projects between academic institutions in Africa and the rest of the world are a fantastic opportunity to share ideas, specialised expertise and new technologies and foster a united approach to solving some of the greatest public health challenges in Africa today. Collaborations also provide a stronger international voice to raise global awareness of the importance of liver disease in Africa among governments, the pharmaceutical industry and the international community.

Acknowledgements. All the authors are grateful to the UK National Institute for Health Research Biomedical Facility at Imperial College London for infrastructure support. MMEC is supported by a Fellowship grant from the Sir Halley Stewart Foundation (Cambridge, UK). All the authors are participant workers in the European Union Framework 7-funded PROLIFICA project in West Africa, which aims to diagnose, treat and follow up a cohort of hepatitis B-positive patients in The Gambia, Sénégal and Nigeria (EC FP7, P34114; www.prolifica.eu). JH is supported by an NHMRC Early Career Post Doctoral fellowship. 


\section{Jessica Howell}

Department of Medicine, Imperial College London, UK, Centre for Population Health, Macfarlane-Burnet Institute, Victoria, Australia, and Department of Medicine, University of Melbourne, Victoria

\section{Nimzing G Ladep}

Department of Medicine, Imperial College London, UK, and Department of Medicine, Jos University Teaching Hospital,

Plateau State, Nigeria

\section{Maud Lemoine}

Department of Medicine, Imperial College London, UK, and Medical Research Council (The Gambia Unit), Fajara, The Gambia

\section{Shevanthi Nayagam}

Department of Medicine, Imperial College London, UK

\section{Papa Souleymane Toure}

Magatte Madoky Diop

Joao Armindo Daveiga

UFR Santé, Thiès University, Thiès, Sénégal

\section{Amina Sow Sall}

Gora Lo

Laboratoire de Bacteriologie Virologie, Le Dantec Hospital, Dakar, Sénégal

\section{Mary M E Crossey \\ Mark R Thursz \\ Simon D Taylor-Robinson}

Department of Medicine, Imperial College London, UK

\section{Mamadou Mourtalla Ka}

UFR Santé, Thiès University, Thiès, Sénégal

\section{Corresponding author: J Howell (j.howell@imperial.ac.uk)}

1. European Association for the Study of the Liver. EASL clinical practice guidelines: Management of chronic hepatitis B virus infection. J Hepatol 2012;57(1):167-185. [http://dx.doi.org/10.1016/j. jhep.2012.02.010]

2. Parkin DM, Bray F, Ferlay J, Pisani P. Global cancer statistics, 2002. CA Cancer J Clin 2005;55(2):74108. [http://dx.doi.org/10.3322/canjclin.55.2.74]

3. Parkin DM, Sitas F, Chirenje M, Stein L, Abratt R, Wabinga H. Part I: Cancer in indigenous Africans 3. Parkin DM, Sitas F, Chirenje M, Stein L, Abratt R, Wabinga H. Part I: Cancer in indigenous Africans -
burden, distribution, and trends. Lancet Oncol 2008;9(7):683-692. [http://dx.doi.org/10.1016/S14702045(08)70175-X]

4. Kirk GD, Lesi OA, Mendy M, et al. The Gambia Liver Cancer Study: Infection with hepatitis B and $\mathrm{C}$ and the risk of hepatocellular carcinoma in West Africa. Hepatology 2004;39(1):211-219. [http:// dx.doi.org/10.1002/hep.20027

5. European Association for the Study of the Liver, European Organisation for Research and Treatment of Cancer. EASL-EORTC clinical practice guidelines: Management of hepatocellular carcinoma. J Hepatol 2012;56(4):908-943. [http://dx.doi.org/10.1016/j.jhep.2011.12.001]

6. Robotin MC, Kansil MQ, George J, et al. Using a population-based approach to prevent hepatocellular cancer in New South Wales, Australia: Effects on health services utilisation. BMC Health Serv Res 2010;10:215. [http://dx.doi.org/10.1186/1472-6963-10-215]

7. Liaw YF, Sung JJ, Chow WC, et al. Lamivudine for patients with chronic hepatitis B and advanced liver disease. N Engl J Med 2004;351(15):1521-1531. [http://dx.doi.org/10.1056/NEJMoa033364]

8. Lopez PM, Villanueva A, Llovet JM. Systematic review: Evidence-based management of hepatocellular Lopez PM, Villanueva A, Llovet JM. Systematic review: Evidence-based management of hepatocellular
carcinoma - an updated analysis of randomized controlled trials. Aliment Pharmacol Ther 2006;23(11):1535-1547. [http://dx.doi.org/10.1111/j.1365-2036.2006.02932.x]

9. World Health Organization.Global policy report on the prevention and control of viral hepatitis in WHO Member States. http://www.who.int/csr/disease/hepatitis/global_report/en/ (accessed 21 April 2014).

10. European Union Framework 7. www.prolifica.eu (accessed August 2014).

11. Shariff MI, Ladep NG, Cox IJ, et al. Characterization of urinary biomarkers of hepatocellular carcinoma using magnetic resonance spectroscopy in a Nigerian population. J Proteome Res 2010;9(2):10961103. [http://dx.doi.org/10.1021/pr901058t]

12. Ladep NG, Dona AC, Lewis MR, et al. Discovery and validation of urinary metabotypes for the diagnosis of hepatocellular carcinoma (HCC) in West Africans. Hepatology 2014;60(4):1291-301. [http://dx.doi.org/10.1002/hep.27264]

13. Shimakawa Y, Yan HJ, Tsuchiya N, Bottomley C, Hall AJ. Association of early age at establishment of chronic hepatitis B infection with persistent viral replication, liver cirrhosis and hepatocellular carcinoma: A systematic review. PLoS One 2013;8(7):e69430. [http://dx.doi.org/10.1371/journal. pone.0069430]

14. Lemoine M, Shimakawa $Y$, Njie R, et al. Food intake increases liver stiffness measurements and hampers reliable values in patients with chronic hepatitis $B$ and healthy controls: The PROLIFICA experience in The Gambia. Aliment Pharmacol Ther 2014:39(2):188-96. [http://dx.doi.org/10.1111/apt.12561]

S Afr Med J 2015;105(3):185-186. DOI:10.7196/SAMJ.8880 